\title{
Calculation Model Using Finite-Difference Method for Energy Analysis in a Concentrating Solar Plant with Linear Fresnel Reflectors
}

\author{
M. Cucumo *, V. Ferraro, D. Kaliakatsos, M. Mele and F. Nicoletti \\ Department of Mechanical, Energetics and Management Engineering (DIMEG), University of \\ Calabria - Via P. Bucci - 87036 Rende (CS) - Italy \\ Email:m.cucumo@unical.it
}

\begin{abstract}
In this paper the geometrical, optical and thermal study and simulation of a concentrator Linear Fresnel Reflector is carried out. Plant performances are analyzed through a mathematical calculation model that allows energy simulations to be made to estimate the productive effectiveness of the plant and to detect the temperature profiles of the various components subjected to concentrated solar radiation.

The absorption system was modeled using a finite difference discretization method. The implementation and resolution of the system of equations obtained, allows the causes of thermal and optical losses to be evaluated and the different types of orientation (North-South or East-West) to be compared by quantifying the energy productivity in the various cases on different days of the year.

The results derived from simulations show how the efficiency of the plant is influenced by some parameters that have been made to vary. In particular, the plant performance is strongly influenced by the index of emissivity of the selective coating that covers the absorber tube.
\end{abstract}

Keywords: Concentrating solar power, Linear Fresnel, Finite-difference method.

\section{INTRODUCTION}

A plant with linear Fresnel reflector is made up of a large number of mirrors that reflects and concentrates solar rays on a system of absorption, placed parallel to the rows of flat mirrors, a few meters from the ground [1]. The absorber is made up of a tube receiver and a secondary reflector which refocuses the beams towards the pipe. Inside the tube flows a heat transfer fluid which absorbs the energy and transports it to a heat exchanger for the production of steam, which subsequently expands in a steam turbine for the generation of electrical energy. Often, it also has a storage tank, which is necessary when moments of little or no solar radiation occur, as in the evening. The fluid used is composed of a mixture of molten salts that can be brought up to an operating temperature of $550{ }^{\circ} \mathrm{C}$ [2].

The requirement of only plane mirrors reduces costs with respect to the production and use of more complex geometries. For this reason this type of plant is named linear.

The primary reflectors are provided with one degree of freedom: the rotation around the axis parallel to the tube receiver. In the present work the analysis of the energy absorbing system modeling using finite difference discretization method, is carried out. With reference to a system installed at $40^{\circ} \mathrm{N}$ latitude, in addition to determining which orientation is more convenient, the aim is to identify which parameters have the greatest effect on yield.

\section{INCLINATION OF PRIMARY REFLECTORS}

Each row of mirrors must be inclined relative to the ground in such a way as the reflected beam is always incident on the receiver tube. Inclinations that assume the mirrors to concentrate the rays on the absorber tube are determined by the position of the sun is in the sky.

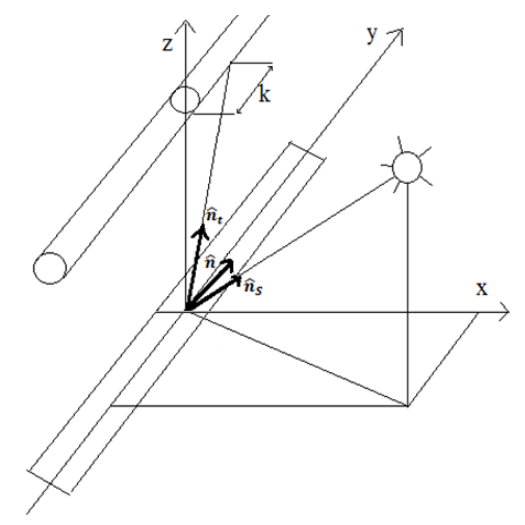

Figure 1. Schematization of the reflection on a panel

Figure 1 shows the three directions of the reflection represented by three unit vectors, respectively:

versor $\hat{n}$ is the normal to the mirror surface; it belongs to the plane $\mathrm{x}-\mathrm{z}$ because the mirror can only rotate around the axis y; 
versor $\hat{n}_{t}$ indicates the direction of the reflected beam incident on the receiver tube;

versor $\hat{n}_{S}$ indicates the direction from which the sun's rays come and is identified by the solar height $\varphi$ and azimuth $a$ corresponding to the day and time considered [3].

The laws of reflection provide two links between the unit vectors: they belong to the same plane and the angle between $\hat{n}$ and $\hat{n}_{t}$ and the one formed between $\hat{n}$ and $\hat{n}_{S}$ are congruent.

Through spherical trigonometry formulas it is possible to derive the relationship between the inclination of a generic reflector and solar coordinates [4]. Indicating with $h$ the height at which the pipe absorber is installed relative to the axis of rotation of the mirror, the generic reflector is positioned at a distance $D$ to the projection of the tube on plane $x$ - $y$ (Figure 2). The angle $\beta$ which forms the normal to the horizontal direction East (Figure 2) is given by the following relationship:

$$
\beta=90^{\circ}-\arctan \frac{\sqrt{1-\cos ^{2} \phi \cos ^{2} a}-\sin \phi}{\cos \phi \sin a}+\frac{1}{2} \arctan \left(\frac{D}{h}\right)
$$

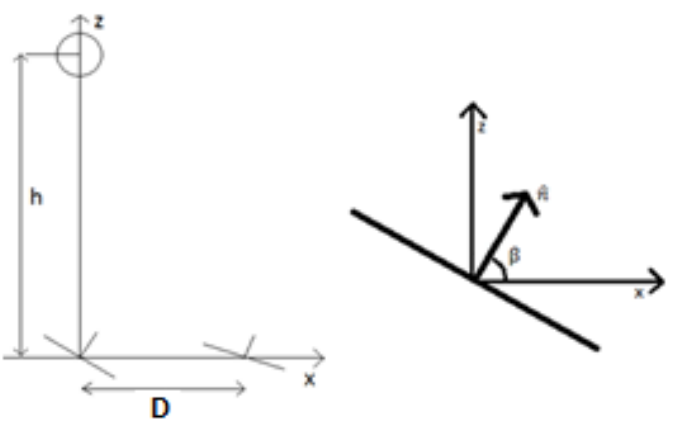

Figure 2. Generic reflector

The term $k$, visible in Figure 1, is notably important. It is representative of the point where the reflected beam hits the absorption system. In fact, the point of arrival on the tube is not located at the same cross-section of the point at which the reflection occurs. With reference to the final part of the plant, it is often the case that the reflected rays, owing to this phase shift, do not affect the receiver. The length $k$, therefore, represents the plant portion in which the reflective surfaces do not provide useful effects. Its value can be obtained again using spherical trigonometry [4]:

$$
k=\frac{\cos \phi \cos a}{\sqrt{1-\cos ^{2} \phi \cos ^{2} a}} \cdot \sqrt{D^{2}+h^{2}}
$$

\section{ENERGY ANALYSIS}

The study is done using a calculation model that adequately describes the causes that affect the optical and thermal efficiency of these systems. The thermodynamic modeling has been developed for a concentrator with linear Fresnel mirrors, equipped with a tubular receiver and a secondary reflector.

\subsection{Modeling of the absorption system}

The absorber was discretized into $n$ elements of constant length equal to $\Delta x$ (Figure 3) [5].

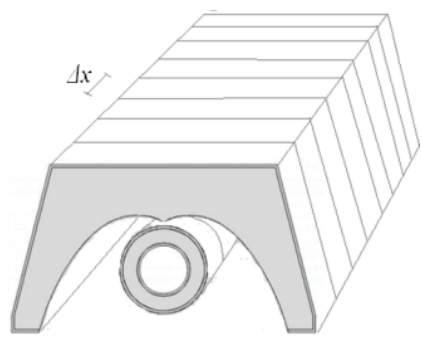

Figure 3. Discretization along the longitudinal axis of the absorption system

The model was created to identify the thermal exchanges between the components of the absorber. Ignoring the radial conduction in metal and glass due to their small thickness, in each section four nodes are fixed to detect the temperatures of:

a) the fluid;

b) the receiver tube;

c) the glass tube;

d) the reflecting surface.

Figure 4 shows the discretization taken along the cross section of the absorption system.

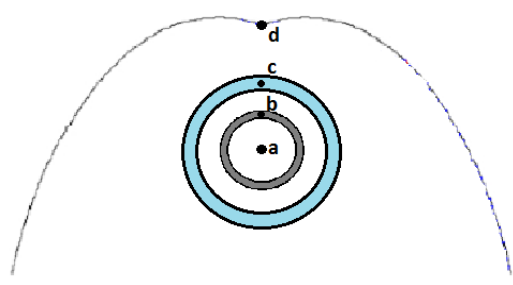

Figure 4. Discretization along the cross section

With this discretization $4 \times n$ nodes have been identified. The simplifying assumptions are:

- temperature of the inner tube uniform at all points of the section; the section

temperature of the glass tube uniform at all points of

- $\quad$ temperature of the secondary reflector uniform at all points of the section;

thermophysical properties (specific heat of the fluid, thermal conductivities) independent of temperature;

stationary process, it is an approximation acceptable because, in the course of the day, the external forcings (the direct radiation normal, the outside air temperature) vary very slowly (in the case of a clear day).

- completely clear sky.

For each node the energy balance equation has been written taking into account conductive, convective and radiative thermal exchanges between adjacent nodes at different temperatures. 


$$
\left\{\begin{array}{l}
\dot{m} c_{p}\left(T_{a}^{i+1}-T_{a}^{i}\right)=\frac{T_{b}^{i}-T_{a}^{i}}{R_{a b}} \\
\frac{T_{b}^{i}-T_{a}^{i}}{R_{a b}}+\frac{T_{b}^{i}-T_{c}^{i}}{R_{i r r, b c}}+\frac{T_{b}^{i}-T_{b}^{i-1}}{R_{c o n d, b}}+\frac{T_{b}^{i}-T_{b}^{i+1}}{R_{c o n d, b}}=\dot{q}_{s, b} \\
\frac{T_{c}^{i}-T_{b}^{i}}{R_{i r r, b c}}+\frac{T_{c}^{i}-T_{d}^{i}}{R_{i r r, c d}}+\frac{T_{c}^{i}-T_{c}^{i-1}}{R_{c o n d}, c}+\frac{T_{c}^{i}-T_{c}^{i+1}}{R_{c o n d}, c}+\frac{T_{c}^{i}-T_{a e}}{R_{e, c}}=\dot{q}_{s, c} \\
\frac{T_{d}^{i}-T_{c}^{i}}{R_{i r r, c d}}+\frac{T_{d}^{i}-T_{d}^{i-1}}{R_{c o n d, d}}+\frac{T_{d}^{i}-T_{d}^{i+1}}{R_{c o n d, d}}+\frac{T_{d}^{i}-T_{a e}}{R_{e, d}}=\dot{q}_{s, d}
\end{array}\right.
$$

The meaning of the symbols used in the system of Eq. (3) is explained below.

Indicating the matrix of thermal conductances with $\|G\|$, the vector of nodal temperatures with $|T|$ and the vector of nodal flows with $|F|$, the system of equations is rewritten using in the following compact form:

$$
\|G\| \cdot|T|=|F|
$$

The vector of nodal temperatures is obtained by solving the system of equations by means of the inversion technique of the thermal conductance matrix.

\subsection{Calculation of thermal resistance}

3.2.1 Convective thermal resistance between the fluid and the inner tube $R_{a b}$

$$
R_{a b}=\frac{1}{h_{i} \cdot \pi \cdot d_{b, \mathrm{int}} \cdot \Delta x}
$$

in which the heat transfer coefficient between the fluid and the inner surface of the tube is indicated with $h_{i} ; d_{b, \text { int }}$ is the internal diameter of the steel pipe, which is indicated by the subscript $b$. The estimation of the heat transfer coefficient is particularly complicated and affect much on the results of the simulation. To calculate this coefficient it is necessary to estimate the value of the Nusselt number in the case of forced convection for internal flow in ducts. The relationships used to estimate it [6] are a function of the Reynolds number and change according to the flow regime that is established inside the tube.

\subsubsection{Axial conductive resistance of the steel pipe $R_{\text {cond,b }}$}

$$
R_{\text {cond }, b}=\frac{\Delta x}{\lambda_{b} \cdot \pi \cdot d_{b, \text { ave }} \cdot s_{b}}
$$

In the equation $\lambda_{b}$ indicates the thermal conductivity of steel, $d_{b, a v e}$ and $s_{b}$ respectively indicate the average diameter and the thickness of the tube.

\subsubsection{Axial conductive resistance of the outer glass $R_{\text {cond,c }}$}

$R_{c o n d, c}=\frac{\Delta x}{\lambda_{c} \cdot \pi \cdot d_{c, a v e} \cdot s_{c}}$

In the equation $\lambda_{c}$ indicates the thermal conductivity of glass, $d_{c, \text { ave }}$ and $s_{c}$ respectively indicate the average diameter and the thickness of the glass.
3.2.4 Radiative resistance between the two tubes $\mathrm{R}_{\text {irr, }} \mathrm{bc}$

The two tubes are coaxial and can be taken of infinite length; in the case of gray surfaces, the radiative thermal resistance is expressed as follows:

$$
R_{i r r, b c}=\frac{\frac{1}{\varepsilon_{b}}+\frac{1-\varepsilon_{c}}{\varepsilon_{c}} \frac{d_{b, e s t}}{d_{c, \text { int }}}}{d_{b, e s t} \cdot \pi \cdot \Delta x \cdot \sigma \cdot\left(T_{b}^{2}+T_{c}^{2}\right) \cdot\left(T_{b}+T_{c}\right)}
$$

where $\varepsilon_{b}$ and $\varepsilon_{c}$ are the emissivity of the two cylinders; $\sigma$ the constant of Stephan-Boltzmann and $T_{b}$ and $T_{c}$ the nodal temperatures.

\subsubsection{Axial conductive resistance of secondary reflector}

$\mathrm{R}_{\text {cond,d }}$

$R_{\text {cond }, d}=\frac{\Delta x}{\lambda_{d} \cdot l_{d} \cdot s_{d}}$

In the equation $\lambda_{d}$ indicates the thermal conductivity of the reflective material, $l_{d}$ and $s_{d}$ respectively indicate the curvilinear length and the thickness of the reflective surface.

3.2.6 Radiative resistance between the outer tube and the secondary reflector $\mathrm{R}_{\text {irr,cd }}$

This resistance is a function of the view factor $F_{c-d}$ between the outer surface of the absorber and the inner surface of the secondary reflector:

$R_{i r r, c d}=\frac{\frac{1-\varepsilon_{c}}{\varepsilon_{c}}+\frac{1}{F_{c-d}}+\frac{1-\varepsilon_{d}}{\varepsilon_{d}} \frac{A_{c, e s t}}{A_{d}}}{A_{c, e s t} \cdot \sigma \cdot\left(T_{c}^{2}+T_{d}^{2}\right) \cdot\left(T_{c}+T_{d}\right)}$

where $A_{c, e s t}$ is the external area of an element of glass tube; $\varepsilon_{d}$ and $A_{d}=l_{d} \Delta x$ are respectively the emissivity and the area of the element of the reflecting mirror.

\subsubsection{External convective resistances $R_{e, c}$ and $R_{e, d}$}

The convective resistances between the glass and the air, and between the secondary reflector and the air, are respectively:

$$
\begin{aligned}
& R_{e, c}=\frac{1}{h_{e} \cdot \pi \cdot d_{c, e s t} \cdot \Delta x} \\
& R_{e, d}=\frac{1}{h_{e} \cdot l_{d} \cdot \Delta x}
\end{aligned}
$$

where $d_{c, \text { est }}$ is the external diameter of the glass tube and $h_{e}$ is the external heat transfer coefficient which depends on the type of convection that develops [6]. The $h_{e}$ values are heavily determined by environmental conditions and, mainly, on the wind speed.

\subsection{Calculation of solar powers}

3.3.1 Solar Power absorbed by the secondary reflector $\dot{q}_{s, d}$

With the aid of the Figure 5 it is observed that the solar radiation directed towards the absorber system is equal to: 
$\dot{q}_{r}=I_{b n} \cdot A \cdot \sin \phi \cdot \rho_{R P}$

where:

- $I_{b n}$ indicates the direct normal irradiance and it is calculated according to the model ASHRAE [7] for estimation of the ground radiation on a clear day:

$$
I_{b n}=A_{1} \cdot e^{-\frac{A_{2}}{\sin \phi}}
$$

where $A_{1}$ and $A_{2}$ are respectively the apparent solar radiation outside the atmosphere and the atmospheric extinction coefficient;

- $A$ represents the surface occupied by primary reflectors, without the gaps between them:

$$
A=n_{R P} \cdot l \cdot \Delta x
$$

where $n_{R P}$ is the number of primary reflectors and $l$ is their width;

- $\quad \rho_{R P}$ is the reflectance of the primary reflectors.

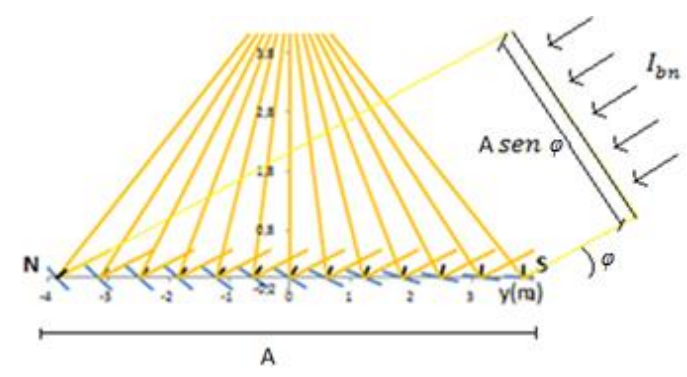

Figure 5. Solar radiation reflected

The reflected radiation in part reaches the receiver tube directly and in part the secondary concentrator to then be reflected toward the tube. The ratio between the diameter of the receiver tube $d_{c, e s t}$ and the length of the aperture of the secondary reflector $l_{a p}$ is called $\gamma$ (Figure 6):

$\gamma=\frac{d_{c, e s t}}{l_{a p}}$

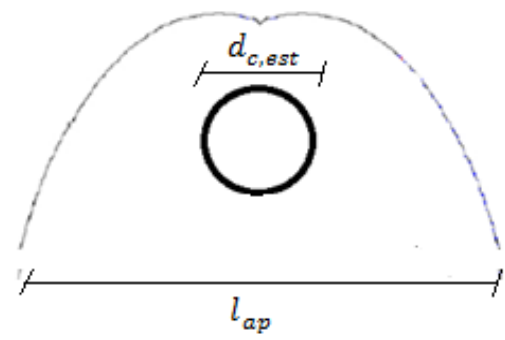

Figure 6. Absorption system

The assumption made is that the concentrated radiation is distributed between the tube and the secondary reflector in a manner proportional to the diameter of the tube and the aperture of the reflector. The solar power absorbed by the node $\mathrm{d}$ is then: $\dot{q}_{s, d}=\dot{q}_{r}(1-\gamma) \alpha_{d}=I_{b n} n_{R P} \cdot l \cdot \Delta x \cdot \sin \phi \cdot \rho_{R P}(1-\gamma) \cdot \alpha_{d}$

where $\alpha_{d}$ is the absorptivity of the secondary reflector.

\subsubsection{Solar power absorbed from the glass envelope $\dot{q}_{s, c}$}

The solar radiation absorbed by the glass tube comes in part directly from the primary reflectors and in part from the secondary reflector. It is therefore:

$\dot{q}_{s, c}=I_{b n} \cdot n_{R P} \cdot l \cdot \Delta x \cdot \sin \phi \cdot \rho_{R P} \cdot \alpha_{c}\left[\gamma+(1-\gamma) \rho_{d}\right]$

where $\rho_{d}$ is the reflectance of the secondary reflector and $\alpha_{c}$ is the absorptivity of the glass tube.

\subsubsection{Solar power absorbed by the steel tube $\dot{q}_{s, b}$}

The solar radiation that reaches the inner tube is given by two components: one coming from the mirrors and the other coming from the secondary concentrator:

$\dot{q}_{s, b}=I_{b n} \cdot n_{R P} \cdot l \cdot \Delta x \cdot \sin \phi \cdot \rho_{R P} \cdot \tau_{c} \cdot \alpha_{b}\left[\gamma+(1-\gamma) \rho_{d}\right]$

where $\tau_{c}$ is the transmittance of the glass tube and $\alpha_{b}$ is the absorptivity of the steel pipe.

In a Fresnel type reflector it can happen that a part of the absorber tube is not illuminated by reflected radiation. If the node considered is not illuminated, the incident solar powers are null. The fraction of lighted tube is calculated as follows:

$f=\frac{L_{p}-k}{L_{p}}$

where $L_{p}$ is the length of the plant.

The ratio between the solar power that reaches the receiver tube and the solar power incident on the reflectors is defined optical efficiency:

$\eta_{o}=\frac{\dot{q}_{s, b} \cdot f}{I_{b n} \cdot n_{R P} \cdot l \cdot \Delta x \cdot \sin \phi}=\rho_{R P} \cdot \tau_{c} \cdot \alpha_{b}\left[\gamma+(1-\gamma) \rho_{d}\right] f$

The total efficiency of the plant is, instead, defined as the ratio between the thermal power transferred to the fluid and the direct solar radiation incident on total area of the mirrors.

$\eta=\frac{P_{u}}{I_{b n} \cdot n_{R P} \cdot l \cdot L_{p} \cdot \sin \phi}$

\subsection{Analysis of the results of the simulations}

The system of equations (Equation 3) has been implemented and resolved within a calculation software. The working fluid used is a mixture of molten salts consists of sodium and potassium nitrates; however, the generality of the equations allows to perform the calculation for any fluid. In Table 1 there are geometrical and optical characteristics of the plant in question. 
Table 1. Geometrical, optical characteristics, emissivity of surfaces

\begin{tabular}{|c|l|l|l|}
\hline \multicolumn{2}{|c|}{ Geometrical characteristics } & \multicolumn{2}{l|}{ Optical characteristics } \\
\hline $\mathrm{n}_{\mathrm{RP}}$ & 13 & $\rho_{\mathrm{RP}}$ & 0.94 \\
\hline $1[\mathrm{~m}]$ & 0.5 & $\rho_{\mathrm{d}}$ & 0.92 \\
\hline $\mathrm{h}[\mathrm{m}]$ & 5 & $\alpha_{\mathrm{d}}$ & 0.08 \\
\hline $\mathrm{d}_{\mathrm{b}, \text { int }}[\mathrm{mm}]$ & 64 & $\tau_{\mathrm{c}}$ & 0.976 \\
\hline $\mathrm{d}_{\mathrm{b}, \text { est }}[\mathrm{mm}]$ & 70 & $\alpha_{\mathrm{c}}$ & 0.02 \\
\hline $\mathrm{d}_{\mathrm{c}, \text { int }}[\mathrm{mm}]$ & 108 & $\alpha_{\mathrm{b}}$ & 0.94 \\
\hline $\mathrm{d}_{\mathrm{c}, \text { est }}[\mathrm{mm}]$ & 114 & Emissivity \\
\hline$l_{\mathrm{ap}}[\mathrm{mm}]$ & 400 & $\varepsilon_{\mathrm{d}}$ \\
\hline$l_{\mathrm{d}}[\mathrm{mm}]$ & 780 & $\varepsilon_{\mathrm{c}}$ & 0.85 \\
\hline $\mathrm{L}_{\mathrm{p}}[\mathrm{m}]$ & 600 & $\varepsilon_{\mathrm{b}}$ (cermet) & 0.89 \\
\hline & & \multicolumn{2}{|l}{} \\
\hline
\end{tabular}

The thermophysical properties of heat transfer fluid and outside air, that laps the glass envelope and the secondary reflector, are shown in Table 2.

Table 2. Thermophysical properties of molten salts and outside air

\begin{tabular}{|l|l|l|l|}
\hline \multicolumn{2}{|l|}{ Molten salts } & \multicolumn{2}{l|}{ Outside air } \\
\hline $\mathrm{c}_{\mathrm{p}}[\mathrm{J} \cdot \mathrm{kg}-1 . \mathrm{K}-1]$ & 1,850 & $\mathrm{c}_{\mathrm{p}}[\mathrm{J} / \mathrm{kg} \mathrm{K}]$ & 1,005 \\
\hline density $\left[\mathrm{kg} / \mathrm{m}^{3}\right]$ & 1,500 & density $\left[\mathrm{kg} / \mathrm{m}^{3}\right]$ & 1.136 \\
\hline$\lambda_{\mathrm{a}}[\mathrm{W} / \mathrm{m} \mathrm{K}]$ & 0.5 & $\lambda_{\text {air }}[\mathrm{W} / \mathrm{m} \mathrm{K}]$ & 0.027 \\
\hline $\operatorname{Pr}$ & 5 & $\operatorname{Pr}$ & 0.72 \\
\hline$\mu[\mathrm{Pa} \cdot \mathrm{s}]$ & 0.005 & $\mu[\mathrm{Pa} \cdot \mathrm{s}]$ & 0.0000191 \\
\hline $\operatorname{Re}(\mathrm{va}=1.35 \mathrm{~m} / \mathrm{s})$ & 25,920 & $\mathrm{Vair}[\mathrm{m} / \mathrm{s}]$ & 1 \\
\hline $\mathrm{Nu}$ & 149 & $\mathrm{Re}$ & 29,738 \\
\hline $\mathrm{h}_{\mathrm{i}}\left[\mathrm{W} / \mathrm{m}^{2} \mathrm{~K}\right]$ & 1,161 & $\mathrm{Nu}$ & 102 \\
\hline & & $\mathrm{h}_{\mathrm{e}}\left[\mathrm{W} / \mathrm{m}^{2} \mathrm{~K}\right]$ & 13 \\
\hline
\end{tabular}

In Table 3 there are the coefficients of thermal conductivity referring to the materials constituting the secondary reflector, the glass envelope and the tube receiver.

Table 3. Coefficients of thermal conductivity

\begin{tabular}{|l|l|}
\hline$\lambda_{d}$ (aluminum) $[\mathrm{W} / \mathrm{m} \mathrm{K}]$ & 290 \\
\hline$\lambda_{c}$ (glass Bo-Si) $[\mathrm{W} / \mathrm{m} \mathrm{K}]$ & 1 \\
\hline$\lambda_{\mathrm{b}}$ (steel) $[\mathrm{W} / \mathrm{m} \mathrm{K}]$ & 20 \\
\hline
\end{tabular}

It is necessary to set the operating conditions of the plant, in particular: inlet temperatures, which are introduced into the system of equations by setting the temperatures of the first nodes of the system; the outside air temperature; the flow rate of the fluid. These data are summarized in Table 4.

Table 4. Operating conditions set

\begin{tabular}{|l|l|}
\hline Operating conditions \\
\hline $\mathrm{T}_{\text {in }}\left[{ }^{\circ} \mathrm{C}\right]$ & 290 \\
\hline $\mathrm{T}_{\mathrm{ae}}\left[{ }^{\circ} \mathrm{C}\right]$ & 20 \\
\hline$\dot{\mathrm{m}}[\mathrm{kg} / \mathrm{s}]$ & 6.51 \\
\hline
\end{tabular}

The flow rate $\dot{m}$ set in Table 4 is determined in relation to the velocity of the fluid of $1.35 \mathrm{~m} / \mathrm{s}$. For example, for a plant located at a latitude of $39^{\circ} \mathrm{N}$, at $12: 00$ on July 21 , the temperatures are shown in Figure 7.

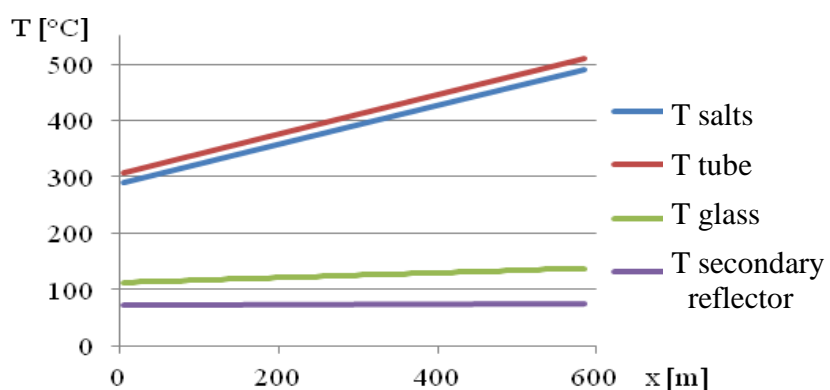

Figure 7. Temperatures obtained for July 21 at 12:00

The temperatures of the fluid and the absorber increase along the direction of motion. The temperature difference between them depends essentially on the value of heat transfer coefficient. The temperature of the glass envelope is maintained at values of about $125{ }^{\circ} \mathrm{C}$, while the secondary reflector is maintained almost at a constant temperature of 70 ${ }^{\circ} \mathrm{C}$. The temperatures reached by the glass and by the secondary reflector are determined by: their own absorptivity which allows them to absorb part of the solar radiation; the outside air temperature and, above all, the external heat transfer coefficient. In these conditions, the molten salt mixture gets in the plant with a temperature of $290{ }^{\circ} \mathrm{C}$ and reaches a temperature of about $497{ }^{\circ} \mathrm{C}$, for a useful thermal power of:

$P_{u}=\dot{m} c_{p}\left(T_{a, \text { out }}-T_{a, \text { in }}\right) \approx 2.5 M W$

It may be useful to set the desired outlet temperature and look for the value of the mass flow, at regime, which with different solar irradiation conditions guarantees the outlet temperature predetermined. The procedure consists in varying the flow rate of the salts with a feedback control until the outlet temperature reaches the desired value. In relation to the previous example (July 21 , latitude $39^{\circ} \mathrm{N}$ ), by setting the outlet temperature equal to $500{ }^{\circ} \mathrm{C}$ the hourly trend of the flow rate of salts which circulate in the system is obtained (Figure 8).

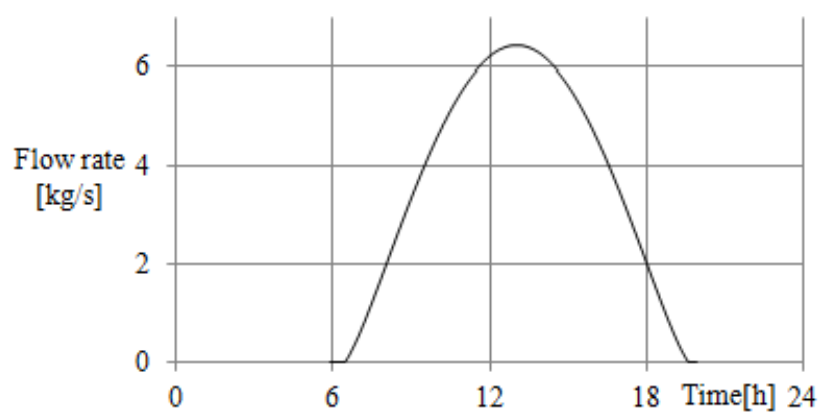

Figure 8. Hourly flow evolving

The integral of the curve of Figure 8 is the quantity of fluid which, in the course of the day, changes its temperature from $290{ }^{\circ} \mathrm{C}$ to $500{ }^{\circ} \mathrm{C}$. The result of the integral, in the specific case, is $183,714 \mathrm{~kg}$. Table 5 shows the energy losses (per unit of time) that occur during operation at 12:00 on July 21. 
Table 5. Power balance

\begin{tabular}{|l|l|l|}
\hline Power balance (kW) \\
\hline Reflected irradiance not incident on tube & 9.9 & $0.31 \%$ \\
\hline $\begin{array}{l}\text { Irradiance absorbed into primary reflectors } \\
\text { and lost by convection }\end{array}$ & 193.4 & $6.00 \%$ \\
\hline $\begin{array}{l}\text { Irradiance absorbed in secondary reflector } \\
\text { and lost by convection }\end{array}$ & 172.3 & $5.36 \%$ \\
\hline $\begin{array}{l}\text { Irradiance absorbed into glass envelope } \\
\text { and lost by convection }\end{array}$ & 57.0 & $1.77 \%$ \\
\hline Irradiance reflected from steel tube & 166.8 & $5.17 \%$ \\
\hline $\begin{array}{l}\text { Power absorbed by the pipe and lost by } \\
\text { irradiance }\end{array}$ & 128.0 & $3.97 \%$ \\
\hline Useful power absorbed by the fluid & $2,495.4$ & $77.42 \%$ \\
\hline Total solar irradiance & $3,223.1$ & $100 \%$ \\
\hline
\end{tabular}

Figure 9 shows the trend of the plant efficiency by varying the emissivity of the coating. It is evident that the lower the emissive power of the tube and the greater the yield of the system. There are different types of coatings that allow a value of $\varepsilon$ less than 0.30 to be obtained for any operating temperature. The coating used, usually, is the cermet which allows an average value of $\varepsilon$ of 0.09 to be obtained.

Figure 10 shows, instead, the performance trends as a function of solar irradiation.

Figure 11 shows graphically the influence of the outside air temperature on total efficiency, which is not very accentuated due to the presence of the glass envelope.

Figure 12, finally, reports the efficiency trend under variable wind speed, which influences the external heat transfer coefficient $h_{e}$ on the surface of the glass and, thus, the temperature of the outer tube.

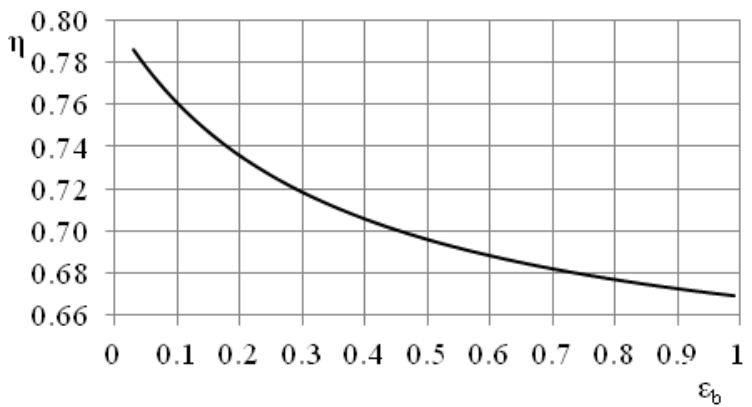

Figure 9. Efficiency against emissivity coating

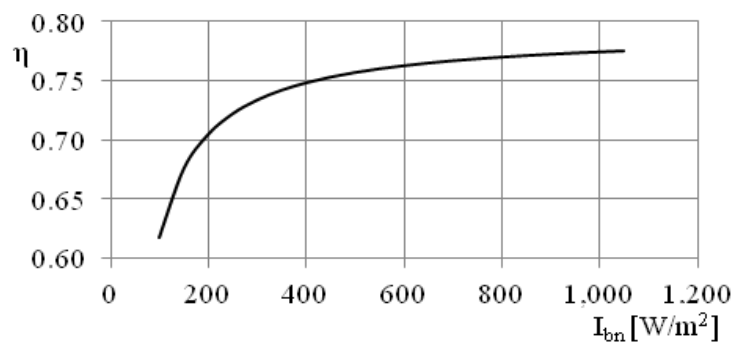

Figure 10. Efficiency as a function of irradiation

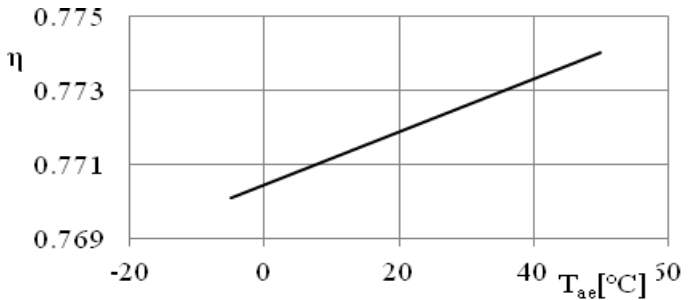

Figure 11. Effects of outside air temperature on the efficiency

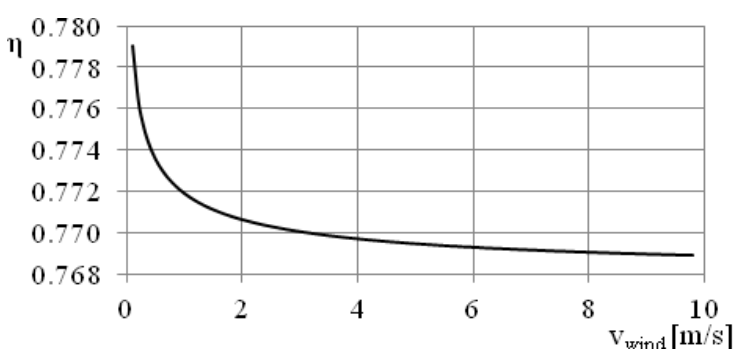

Figure 12. Efficiency as a function of wind speed Figure 13 shows the trends of fluid and other components temperatures, carried out for a plant of 100 meters length, with orientation N-S, on 21 December at 12:00.

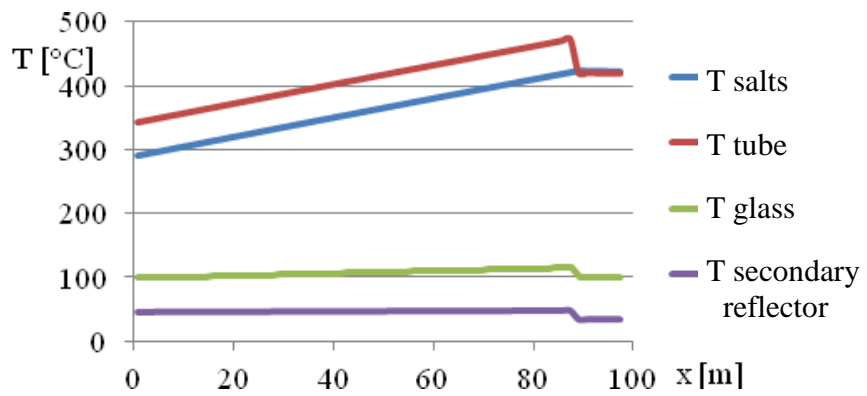

Figure 13. Temperature trends

In the first length, the temperature of the tube is maintained higher than the fluid, in the second part of the tube it drops rapidly going slightly below that of the fluid, which also reverses its slope. This occurs since the latter part of the absorber (of length $k$ ) is not affected by the reflected rays. In this length, in fact, the fluid is cooled as it gives thermal energy to the absorber tube that disperses through radiation to the outside. For this plant, placed at a latitude of $39^{\circ} \mathrm{N}$ on December 21 at 12:00, according to its geometric characteristics, the length of tube not illuminated $k$ is about 10.4 meters. The yield in the winter solstice, drops down to $65 \%$. The reduction is also due both to the low value of irradiation, which causes the reduction of the flow rate and, then, of the internal heat transfer coefficient and to the low outside air temperature, set equal to $5^{\circ} \mathrm{C}$.

Analysing the results deriving from the simulations, the efficiency curve of the first order is obtained, generally expressed by the following equation: 
$\eta=\eta_{o}-a_{1} \frac{\bar{T}_{f}-T_{a e}}{I_{b n}}$

where:

- $\quad a_{l}$ is a parameter that describes the thermal losses of the collector;

- $\quad \bar{T}_{f}$ is the average temperature of the fluid between inlet and outlet.

By performing different simulations, by varying the temperature of the inlet fluid, the outside air temperature and other quantities, it was extrapolated the graph of Figure 14. This graph shows the efficiency curves, in stationary conditions, with reference to different values of emissivity of the surface coating of the receiver tube.

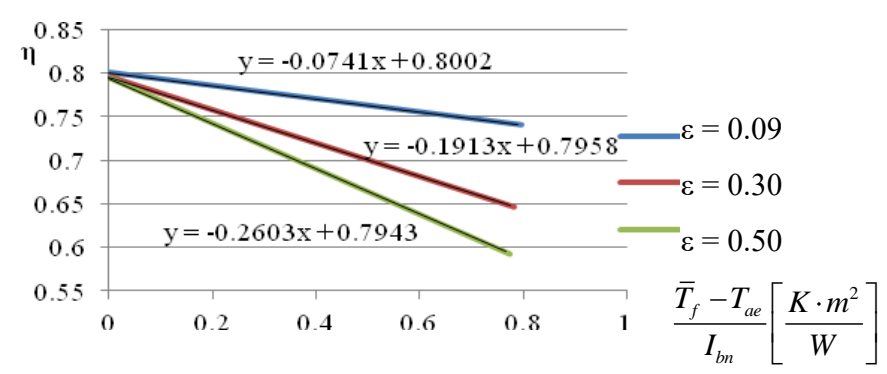

Figure 14. Efficiency curves for different values of emissivity of the coating

\subsection{Influence of the plant orientation}

A Linear-Fresnel plant can be disposed according to two types of orientation. It is said that it is oriented in N-S direction if the axis of the tube coincides with the NorthSouth line; it is oriented E-W if the axis coincides with a straight East-West line. In particular, the orientation determines, at various hours of the day, different values of the length of the tube which is not radiated. For small plants this effect has significant influence on the performance. For the plant used in previous simulations but with a length of 30 meters, two graphs that show trends of the absorbed power and efficiencies for both types of orientation, for the Spring equinox, are presented below. Figures 15 and 16 show how the plant with $\mathrm{N}-\mathrm{S}$ orientation can better direct rays towards the pipe at sunrise and sunset, while the one with E-W orientation directs them better in the middle of the day.

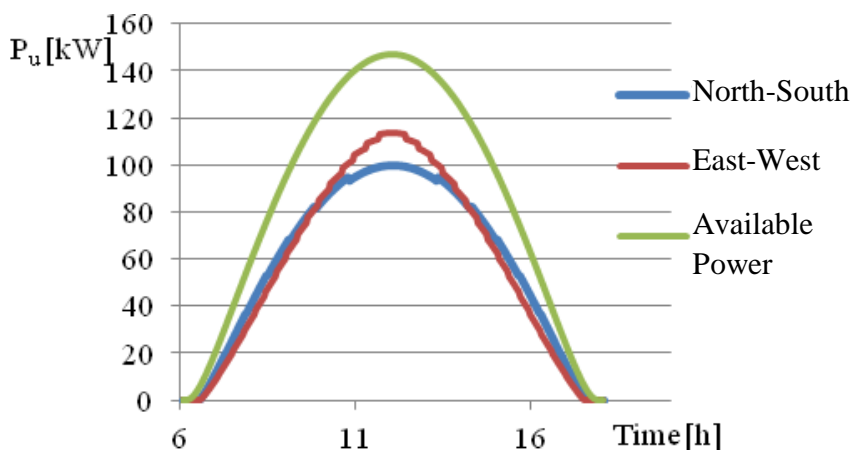

Figure 15. Available power and absorbed power for N-S and E-W plants on March 21

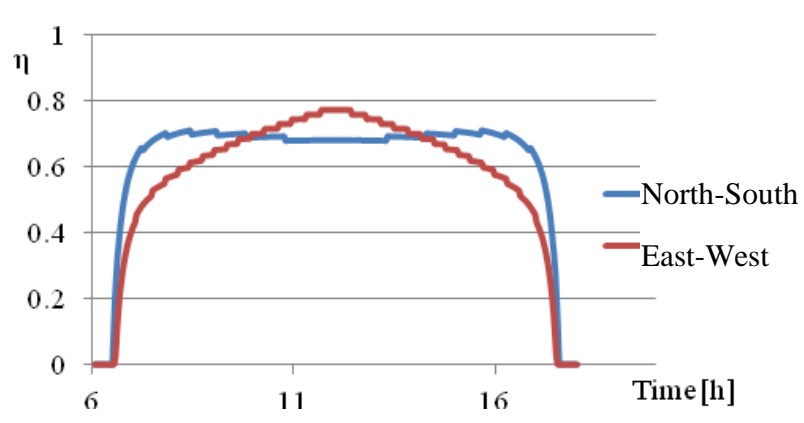

Figure 16. Efficiency for plants N-S and E-W on March 21

Ultimately, to assess which orientation produces more heat energy, it is necessary to solve the integral of the curve of absorbed power. Table 6 presents the values of thermal energy produced in the days of solstices and equinoxes.

Table 6. Produced and available energy, efficiencies

\begin{tabular}{|l|l|l|l|l|l|l|l|l|}
\cline { 2 - 9 } \multicolumn{1}{c|}{} & \multicolumn{2}{l|}{ March 21 } & \multicolumn{2}{l|}{ June 21 } & \multicolumn{2}{l|}{ September 22 } & \multicolumn{2}{l|}{ December 21 } \\
\cline { 2 - 9 } \multicolumn{1}{c|}{} & N-S & E-W & N-S & E-W & N-S & E-W & N-S & E-W \\
\hline $\begin{array}{l}\mathrm{E}_{\mathrm{u}} \\
{[\mathrm{MJ}]}\end{array}$ & 2,544 & 2,548 & 3,625 & 3,342 & 2,345 & 2,342 & 922 & 1,080 \\
\hline $\begin{array}{l}\text { Etot } \\
{[\mathrm{MJ}]}\end{array}$ & 3,717 & 3,717 & 4,877 & 4,877 & 3,448 & 3,448 & 1,588 & 1,588 \\
\hline$\eta_{\text {tot }}$ & 0.684 & 0.685 & 0.743 & 0.685 & 0.680 & 0.679 & 0.581 & 0.680 \\
\hline
\end{tabular}

It is noted that at the equinoxes, the orientation does not affect the yield of the system. In summer, the collector with $\mathrm{N}-\mathrm{S}$ orientation can produce more heat energy than the same with the E-W orientation. Vice versa, in the winter period, it is the collector E-W that provides the best performances. The average daily efficiency reported in Table 6 is defined as the ratio of the energy produced $E_{u}$ to the energy available during the day $E_{t o t}$ :

$\eta_{t o t}=\frac{E_{u}}{E_{t o t}}$

In Figure 17 the results obtained for the two orientations for all months of the year are shown in a bar chart. The value of average energy produced daily was estimated and it was found that the collector with North-South orientation is able to provide better performance.

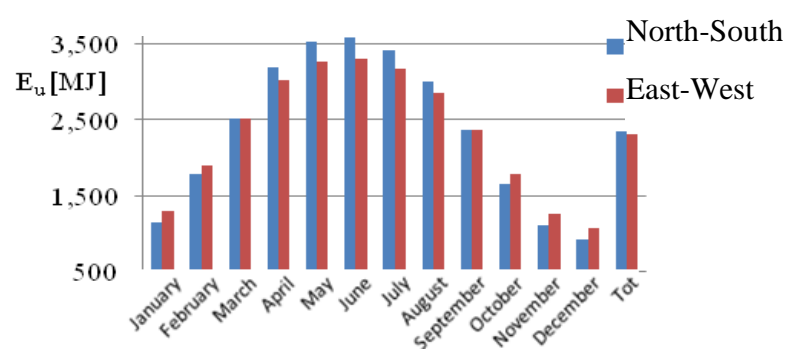

Figure 17. Energy produced the $21^{\text {th }}$ day of month

\section{CONCLUSIONS}

In this work the performance of a linear Fresnel concentrator was analyzed. A mathematical model was realized, it is based on the finite difference method and allows 
to determine the temperature profiles of the receiver components and the influence of different parameters on the performance of the plant. It was therefore possible to observe the emissivity of the selective coating that covers the absorber tube has great importance and constitutes the main cause of heat losses.

Thanks to the created model it was also possible to estimate the productive efficiency of the system for the two orientations and for different months of the year. The model created and implemented allows, therefore, at any section of the plant, detection of the temperatures and the powers exchanged between the components, in order to evaluate optical and thermal losses and to identify the parameters on which it is convenient to intervene to increase the efficiency of the same. The simulations show that the system with N-S orientation provides the best performance.

\section{REFERENCES}

[1] M. Hannane Regue, T. Benchatti, A. Medjelled, A. Benchatti, "Improving the performances of a solar cylindrical parabolic dual reflection Fresnel miror (experimental part)," International Journal of Heat and Technology, vol. 32, no. 1\&2, pp. 171-178, 2014.

[2] K. Zhang, J. Du, X. Liu and H. Zhang, "Molten salt flow and heat transfer in paddle heat exchangers," International Journal of Heat and Technology, vol. 34, Special issue no. 1, pp. 43-50, 2016. DOI: 10.18280/ijht.34S106.

[3] M. Cucumo, D. Kaliakatsos, V. Marinelli, "General calculation methods for solar trajectories," Renewable Energy, vol. 11, no. 2, pp. 223-234, 1997.

[4] F. Nicoletti, "Studio del Sistema di Inseguimento per un Impianto Solare a Concentrazione con Riflettore di Fresnel," M.S. thesis, Dept. DIMEG, Unical, Rende (CS), 2015.

[5] M. Falchetta, A. Gambarotta, I. Vaja, M. Cucumo, C. Manfredi, "Modeling and simulation of the thermo and fluid dynamics of the "Archimede Project" solar power station," presented at the 19th International Conference on Efficiency, Cost, Optimization, Simulation and Environmental Impact of Energy Systems, ECOS 2006, Aghia Pelagia, Crete, Greece, July 12-14, 2006, pp. 1499-1506.

[6] Valerio Marinelli, Giuseppe Oliveti, Adolfo Sabato, Elementi di Trasmissione del calore, Pitagora Ed., Bologna.

[7] ASHRAE Handbook, Fundamentals, New York, 1989.

\section{NOMENCLATURE}

$\|G\|$ matrix of thermal conductance, W.K-1

$|F|$ vector of nodal flows, W

$|G| \quad$ vector of nodal temperature, $\mathrm{K}$

a solar azimuth, rad

$a_{1} \quad$ thermal losses of collector, W.m-2.K

A surface occupied by reflectors, $\mathrm{m} 2$

$A_{l} \quad$ extra-atmospheric apparent solar radiation, W.m-2

$A_{2} \quad$ atmospheric extinction coefficient

$A_{c, \text { est }} \quad$ external area of an element of glass tube, $\mathrm{m} 2$

$A_{d} \quad$ area of an element of secondary reflector, m2

$c_{p} \quad$ specific heat, J.kg-1.K-1

$D \quad$ distance between tube and reflector, $\mathrm{m}$

$E_{\text {tot }} \quad$ energy available in a day, MJ

$E_{u} \quad$ energy produced in a day, MJ

$f \quad$ dimensionless fraction of lighted tube

$F_{c-d} \quad$ view factor between external glass tube and secondary reflector surfaces

$h \quad$ height of the tube, $\mathrm{m}$

$h_{i} \quad$ internal heat transfer coefficient,W.m-2.K

$h_{e} \quad$ external heat transfer coefficient, W.m-2.K

$I_{b n} \quad$ direct normal irradiance, W.m-2

$k \quad$ length of tube not irradiated, $\mathrm{m}$

$l \quad$ primary reflector width, $\mathrm{m}$

$l_{d} \quad$ curvilinear length of secondary reflector, $\mathrm{m}$

$l_{a p} \quad$ aperture of secondary reflector, $\mathrm{m}$

$L_{p} \quad$ length of the plant, $\mathrm{m}$

$\dot{m} \quad$ flow rate, kg.s-1

$n \quad$ number of longitudinal nodes

$\hat{n} \quad$ versor normal to primary reflector

$\hat{n}_{S} \quad$ sun's rays versor

$\hat{n}_{t} \quad$ reflected beam versor

$n_{R P} \quad$ number of primary reflectors

$\mathrm{Nu} \quad$ Nusselt number

$\operatorname{Pr} \quad$ Prandtl number

$P_{u} \quad$ useful thermal power, W

$\dot{q}_{r} \quad$ solar irradiance incident on mirrors, W

$\dot{q}_{s} \quad$ solar irradiance absorbed, W

$R a \quad$ Rayleigh number

$R_{a b} \quad$ convective resistance between $a$ and $b$ nodes, K.W-1

$R_{\text {cond }} \quad$ axial conductive resistance, $\mathrm{K} . \mathrm{W}-1$

$R_{e, c} \quad$ convective resistance between glass tube and external air, K.W-1

$R_{e, d} \quad$ convective resistance between secondary reflector and external air, K.W-1

Re Reynolds number

$R_{\text {irr, } b c} \quad$ Radiative resistance between $b$ and $c$ nodes, K.W-1

$R_{\text {irr,cd }} \quad$ Radiative resistance between $c$ and $d$ nodes, K.W-1

$s \quad$ thickness, $\mathrm{m}$

$T$ temperature, ${ }^{\circ} \mathrm{C}$

$T_{a, \text { out }} \quad$ fluid outlet temperature, ${ }^{\circ} \mathrm{C}$

$T_{a e} \quad$ outside air temperature, ${ }^{\circ} \mathrm{C}$

$\bar{T}_{f} \quad$ Average fluid temperature between inlet and outlet, ${ }^{\circ} \mathrm{C}$

$T_{\text {in }} \quad$ inlet temperature, ${ }^{\circ} \mathrm{C}$

$v \quad$ velocity, m.s-1

\section{Greek symbols}

$\alpha$

$\rho$

$\beta$ absorptivity reflectance inclination of primary reflector, $\mathrm{rad}$

Ratio between external diameter of glass tube and aperture of secondary reflector longitudinal distance of nodes, $\mathrm{m}$ emissivity plant total efficiency plant optical efficiency average daily efficiency thermal conductivity of aluminum, W.m-1.K thermal conductivity of glass Bo-Si, W.m-1.K thermal conductivity of steel, W.m-1.K dynamic viscosity, kg.m-1.s-1 Stephan-Boltzmann constant,W.m-2.K-4 transmittance solar height, rad 


\section{Subscripts}

a molten salts

air air

ave average

$b \quad$ inner tube

c glass tube

d Secondary reflector int internal

est external

$R P \quad$ primary reflectors

Apexes

$i \quad$ longitudinal element 